\title{
A LÍNGUA SÂNSCRITA E A CULTURA
}

\section{JORGE BERTOLASO STELLA}

Não ha língua que não tenha a sua utilidade. E' fato porém que ha idiomas que se distinguem, mais do que outros, como instrumentos do saber. A língua sânserita mostra o seu valor particular como veículo de cultura.

A historia desta língua é sobremaneira interessante e várias são as suas etapas no desenvolvimento da cultura indiana. Tem ela perto de cinco mil anos. Não é lingua morta, no verdadeiro sentido da palavra, como o hitita, o tocario, o etrusco, etc. Foi sempre viva e viva ainda é hoje, falada na India pelas pessoas cultas. E' claro que, como todas as linguas, especialmente de povos cultos, passou por varias transformações em seu longo trajeto historico.

A importancia do sânscrito não consiste tanto na sua antiguidade, quanto no modo perfeito como tem sido conservado e na abundancia de formas que êle apresenta.

O livro mais antigo da literatura indiana, o Rig-Vèda, é uma coleção de 1.028 hinos, contendo mais ou menos 160.000 palavras. Não se trata, pois, de poucos fragmentos ou breves inserições, pondera Pizzagalli, mas de um insigne monumento do pensar humano, não confiado ao marmore ou ao bronze, porém à memoria dos homens, vida do seu espirito. luz da sua alma, base da sua civilização e do seu direito.

Notaveis coincidencias lexicas, correspondencias literarias de frases inteiras e de elementos religiosos e sociais nos hinos do Rig-Veda e nas estrofes do Avesta, os dois mais antigos documentos da civilização indiana e iranica, demonstram haver existido um longo periodo em que os povos, possuidores desses documentos, tinham vida em comum. 


\section{$-150-$}

Foi o sânscrito que deu a Eugenio Burnouf a chave com a qual descobriu a lingua zenda, abrindo destarte o caminho para a filologia do Avesta.

O sânscrito não é um simples dialeto, mas uma língua literaria, imposta no principio como lingua sagrada e hieratica, e depois elaborada pelos gramaticos, especialmente pelo célebre Pánini, que fixou as leis nos 4.000 aforismos. A vitaiidade desta lingua é demonstrada nas varias fases de seu longo percurso. Toda a civilização da India reflete-se nesta lingua. Ela muda o seu lexico, a mesma estrutura gramatical, da frase verbal passa para a nominal e da mais simples estrutura sintatica passa à mais complexa. Os compostos, raros no Veda, tornam-se frequentes, no sânscrito classico. Modos e tempos, usados no Veda, desaparecem mais tarde, quasi totalmente. Não se modifica assim uma língua morta. Transformar-se é viver.

Para o estudioso da linguagem a fase mais interessante do sânscrito é a mais antiga, a do sânscrito védico, a língua dos hinos, rica de formas, muito proxima à lingua do Avesta e das inscrições dos Aquemenides. A crítica moderna, dizem alguns, soube investigar, na língua do Veda, variedades dialetais e soube também distinguir as formas, por assim dizer, modernizadas das genuinas e antigas. Nāo obstante a língua do Rig-Veda é uma só. No substrato da lingua dos hinos de caráter sacerdotal, investigou-se a língua falada, também fora dos circulos sacerdotais, lingua que representaria a fase mais antiga do que aquela que foi mais tarde o pâli ou a língua do budismo.

No periodo seguinte ao Rig-Veda, cessa para a lingua o verdadeiro período de vida espontanea e a obra regularizadora da escola começa a fazer-se sentir. A lingua das pessoas cultas tende a adquirir estabilidade e o movimento linguistico espontaneo continua nas baixas camadas sociais entre o povo. Termina assim. para a língua douta, a creação de novas formas e não só isto, mas começa o período das perdas. A língua douta tende à mais simp!icidade e modalidade. As formas do conjuntivo perdem-se e as do optativo são reduzidas. Das doze formas do infinito, que aparecem no Veda. permanece uma só. Casos de fusão ou de sincretismo apresentam-se na declinação. Faz-se sen- 
tir uma tendencia ao nivelamento, devido, em parte, à obra da escola e, em parte, ao influxo sucessivo da língua falada. Sobretudo muda-se o lexico. Uma grande redução de formas gramaticais em confronto com o Rig-Veda apresenta a língua do Atharvaveda e dos Brahmanes e particularmente o sânscrito classico, que foi fixado pelos gramaticos, cuja obra culminou com Pánini, no 4 . $^{\circ}$ seculo A.C. Por ter sido fixada sobre regras gramaticais foi chamada "sânscrita" (língua) perfeita, elaborada, refinada, purificada", denominação esta que aparece pela primeira vez no Ramáyana, em oposição às linguas indo-arias, diferentes umas das outras, porém hoje todas fundidas sob a designação comum de "medio indiano" que, forjadas diretamente sobre o linguajar indo-ario da mesma região, foram chamadas "prakritas", "naturais não elaboradas".

E' riquissima a literatura da India.

O Rig-Veda é o documento literario mais antigo, não somente da India, mas do povo ariano e em certo sentido do mundo todo. No sentir de $M$. Müller, os hinos sagrados, que estão contidos nesse documento, não têm rival na literatura de todos os povos. O Rig-Veda ou Veda dos "rc", versos laudativos ("rg-vedah", de veda — raiz "vid" conhecer, ciencia, ciencia sagrada e de "rc", versos, estancias, estrofes, hinos), é a coleção liturgica de hinos dos povos arianos dirigidos às divindades.

Há quatro vedas, que a tradição admite como sendo inspirados: 1. ${ }^{\circ}$ o Rig-Veda, 2. ${ }^{\circ}$ o Sâmaveda, 3. ${ }^{\circ}$ o Tajurveda, $4 .^{\circ} \circ$ Atharvaveda. O Vèda "stricto sensu" é o Rig. O Rig-Veda foi transmitido ora!mente de família em família, de geração em geração, entre os poetas vedicos. Supōe-se que data de 1.500 anos antes de Cristo. A lingua do Rig-Veda, já tratada acima, dispōe apenas de uma sintaxe elementar, segundo Oldemberg. $O$ antigo indiano do Rig-Veda, diz Mansion, é o antigo indo-europeu, ainda bastante reconhecido, apesar das modificações varias sofridas durante o período ariano comum. A declinação do antigo indiano é a imagem mais fiel que essa lingua nos legou da declinação indo-européia. Pizzagalli afirma ser o antigo indiano, nas suas varias formas, mais na morfologia do que na fonetica e na sintaxe, a lingua cuja estrutura mais se aproxima da estrutura da língua ariana indo-européia. 


\section{$-152-$}

O Rig-Veda portanto, escrito no antigo indiano, é um documento precioso para o estudo da filologia.

O Mahábharata, com mais de 220.000 versos possue um total de 83.246 estrofes. Mais do que um poema épico, é uma verdadeira enciclozedia. arquivo precioso do pensamento indiano e chamado o gigante dos poemas. Data mais ou menos do quarto século A.C. Um dentre os episodios deste monumento literario, a Bhagavad-gîta, atraiu a atenção dos estudiosos. E' um poema religioso-filosofico, chamado a Biblia da India. Não ha livro mais lido do que este e Emilio Burnouf, em sua apreciação, afirma que provavelmente é o mais belo que saiu das mãos dos homens. O Mahábharata é escrito em sânscrito classico, como também o Ramáyana.

O Ramáyana possue 24.000 estrofes. Foi escrito mais ou menos no terceiro seculo A.C. Ha certa semelhança entre o Ramáyana e a lliada, assim como, pela natureza do assunto, o Mahábharata tem certa correspondencia com a Odisséia. O Ramáyana é chamado a "Bíblia da bondade". Pela descrição da natureza, escolhas das imagens poeticas e. especialmente, pela pureza que anima Râma e a esposa. considera-se a epica de Válmiki uma das mais altas concepçōes poeticas do gênio humano.

Os Puranas reiacionam-se à épica pelo seu conteúdo, traço de fundo comum e pelo seu caráter enciclopedico e são volumosas obras didaticas, compostas com finalidade religiosa. Como obra enciclopedica e vasta têm como objeto. entre muitas outras finalidades, a criação do mundo, a origem dos deuses, o nascimento do primeiro homem, descrição do céu e da terra, dos infernos, mitos cosmologicos, as quatro épocas do mundo, o diluvio. Contém cerimonias para nascimento, morte e a exposição de sistemas filosoficos. Finalmente encontram-se aí noçōes de astronomia, astrologia, construções de casa, de política, de arte da guerra, de direito, medicina, matematica, poesia e gramatica.

Os Puranas são 18, constituidos de 400.000 estrofes. Não é facil determinar a época em que foram escritos. A matéria dos textos reunidos. de épocas diversas, atesta que se relacionam aos Vedas, especialmente ao Mahabhárata, mas a sua elaboração final parece não ser anterior ao VI século da era cristã. A língua dos Puranas é do tipo classico. 
Não fazendo referencia a outros da literatura da India, convém dizer uma palavra sobre os proverbios indianos. A literatura gnomica, fruto da experiencia da vida e do espírito de observação, é patrimonio comum dos povos civilizados. O povo indiano, porém, leva a palma, não sòmente pela variedade do assunto, profundidade e elegancia de forma, mas também devido a ser veículo do seu pensamento, a lingua sânscrita. Esse idioma é porventura o mais perfeito que haja existido no mundo, na opiniāo de Formichi. O sânscrito, língua sintetica, pode explicar ou exprimir com um verso ou metade de um verso aquilo que nós outros, em nossa lingua analítica, somos obrigados a dizer com longas frases. Dado pois um instrumento linguistico dessa natureza, era natural que se desenvolvesse, nesse povo, o genero literario de aforismo.

As fontes das sentenças gnomicas encontram-se no Rig-Veda, Ramáyana, Mahabhárata, Hitopadeça e Panciatantra, livro este que, depois da Bíblia, foi o mais difundido no mundo, havendo, julga-se, 200 traduções em cêrca de 60 linguas. O numero de proverbios da India atinge cerca de 19.000 que refletem a sabedoria dos séculos.

O elemento essencial para a filosofia é, sem duvida, a língua. Qualquer conclusão que se tira da observação imediata dos fatos e referente às mais altas questões da metafisica e da logica, é, no fundo, um produto da língua. O sânscrito é uma língua eminentemente filosofica, apta a depositar em um só vocábulo dois ou três conceitos abstratos, diz Formichi. Assim "hetu" que significa "causa" e com o sufixo "mat" passa a designar tudo aquilo que é produto de uma "causa" ("hetumat"). A "hetumat" podese ainda acrescentar o sufixo "tvam" que serve para formar os abstratos ("Bhúmi" terra, "Bhúmitvam" a condição de ser terra; "nâri" muiher, "nârîtvam" feminilidade) e obter a palavra "hetumatvam" que significa "a condição de ser aquilo que é produto de uma causa".

Segundo as informações de Jaina, havia, no seu tempo, 363 sistemas filosoficos diferentes. A terminologia filosofica indiana é riquissima. Ha um livro de 1037 paginas, escrito por Bh$\hat{\hat{L}}$ mâcârya Jhalakêkar intitulado Nyâyakosa ou dicionario dos termos teenicos do Nyâya. 
A língua sânscrita é uma grande auxiliar da Historia das Religiōes. E' bastante pensar na escola chamada Filologica, fruto do sânscrito, na qual trabalharam sanscritólogos de fama, destacando-se entre eles Max Müller. Este, em 1891, considerou a maior descoberta do século $X \mid X$, no campo da historia antiga da humanidade, esta simples equaçāo etimologica: sânscrito "Dyaus — pitar" = grego "Zeus — pater" = latino "lupiter" = antigo norueguês "Tyr"... Ela atesta que os nossos antepassados não só falavam a mesma lingua do povo indiano, mas também que todos, um dia, tiveram a mesma religião e adoravam a mesma divindade suprema sob o mesmo nome de "Céu Pai".

As obras já mencionadas, vasadas em sânscrito, têm um carater profundamente religioso. Basta este conceito para comprovar: "O estudo do Rig-Veda é designado, com razão, "a escola superior de teologia, de ciência das religiōes".

$O$ sânscrito teve grande influencia na filologia. A linguistica, segundo Boitz, encontrou o seu microscopio no sânscrito. E' a verdadeira base para interpretação, apreciaçāo e conhecimento das formas gramaticais na grande familia e possue o mais perfeito organismo linguístico do mundo. Riquíssimo de sons, de desinencias, de declinações, de flexōes, de vocabulos e, sobretudo, possue liberdade em agrupar em longos compostos as palavras que, pela sua justaposição, podem oferecer este ou aquele sentido.

William Jones já havia dito que a lingua sânscrita é admiravel em sua estrutura; mais perfeita que o grego, mais rica que o latim e mais melodiosa que ambas. C. Curtius, por seu turno, deelarou que a língua sânscrita é maravilhosa pela sua regularidade e pela transparencia de seu organismo.

O sânscrito é considerado o fundamento da gramatica comparada das linguas indo-européias e é tido como lingua classica por excelencia. A Lingüística Comparativa deve a sua existenci. ao sânscrito. Ele pôs em evidencia as leis da transformação gradual das línguas. Foi o sânscrito, diz Fumi, que serviu de intermediario entre as formas do grego e do latim e que fez desse modo reconhecerem-se as leis das passagens fonéticas e dai os graus e os direitos de afinidade entre um dado numero de linguas. 
E' sabido que a palavra é a descrição de um objeto, que se distingue de outros por uma ou mais caracteristicas fundamentais. Quanto mais uma lingua se afasta das origens e se torna lingua derivada ou evoluida, tanto mais cresce a opacidade dos seus vocabulos.

A lingua sânscrita, base de toda pesquisa glotologica e morfologica, foi chamada a irmã mais velha das línguas indo-européias. E' a que, mais do que qualquer outra, conservou puro o tipo de familia e é, por esse motivo, de capital importancia para a comparação dos idiomas indo-europeus, projetando luz sobre suas irmãs. Ela mostra ainda transparente o significado primitivo da palavra. Esse fato comprova-se com os exemplos: A palavra pai, pater do latim, patér do grego, recebe luz do sânscrito pitâ (raiz pâ proteger) e significa protetor da família, o que nutre, e que governa; mãe mater do latim, méter do grego, do sânscrito mâtâ (raiz mâ medir) e significa a que mede, economiza, destribue aos membros da família (na opinião de Formichi) porém, segundo Bopp, significa a que gera, aquela que produz; Deus, Deus do latim Theós do grego e do sânscrito Deva (raiz div resplandecer, brilhar) significa luz, o que brilha, que resplandece, além de outros exemplos.

Como se percebe, o sânscrito é uma lingua indispensavel para a filologia. Por essa causa tem-se dito, com razão, que o sânscrito está para a filologia comparada como a matemática para a astronomia. 